\title{
MiCROPROPAGACIÓN Y DETERMINACIÓN \\ CROMOSÓMICA DEL GÉNERO CROTON PRODUCTORES \\ DE LÁTEX
}

\section{Micropropagation AND CHROMOSOMAL \\ DETERMINATION OF THE LATEX PRODUCING \\ GENDER CROTON}

\author{
Astriht Ruiz Ríos ${ }^{1}$ y María de Lourdes Tapia y Figueroa ${ }^{2}$ \\ ${ }^{1}$ Universidad Nacional de San Martín-Tarapoto, Jr. Dos de Mayo Nº340, Moyobamba, Perú \\ ${ }^{2}$ Universidad Nacional Agraria, La Molina, Lima, Perú
}

\section{RESUMEN}

El presente trabajo de investigación tuvo como objetivos: determinar las diferencias en el desarrollo invitro deyemas provenientes de plantas juveniles de Croton productores delátex; evaluar la respuesta a la aclimatación de plántulas de Croton de mejor comportamiento in vitro y determinar el número cromosómico de individuos seleccionados del género Croton productores de látex. El medio de cultivo para la introducción in vitro fue determinado evaluando el comportamiento de Croton draconoides en cinco tratamientos cuyo medio básico fue el de Murashige y Skoog (MS) tomando en consideración que las especies en estudio pertenecen al mismo género. Las yemas provenientes de plantas juveniles de Croton productor de látex color vino fueron las que mejor comportamiento tuvieron en el medio de cultivo seleccionado (MS + 0,01 mg/l de ANA + 0,1 mg/l de BAP y $\mathrm{AG}_{3}+20 \mathrm{ml}$ de agua de coco), presentando mayor altura, número de hojas y porcentaje de sobrevivencia en relación a Croton productor de látex color rojo y ocre. Las plántulas de Croton productor de látex color vino, previamente enraizadas in vitro, fueron llevadas a aclimatación, probando cuatro substratos, determinándose que las respuestas de las plántulas varían de acuerdo a la composición del sustrato, las condiciones de riego (nebulización), el control de hongos (benlate al $0.1 \%$ y la aplicación del bioestimulante biogen 1 al 0,1\%. El número cromosómico determinado en las plantas del género Croton productoras de látex rojo, vino y ocre fue de 40.

Descriptores: Croton, látex, in vitro, micropropagación, plántulas, explantes

\begin{abstract}
The present investigation had the purpose of: determining the differences in the in vitro development of buds from Croton young plants of latex producers; to evaluate the response to the acclimatization of Croton's plantulas with better behavior in vitro, and to determine the chromosomal number of selected individuals of Croton latex producers. The culture medium for the in vitro introduction was determined evaluating the behavior of Croton draconoides in five treatments with the basic medium Murashige and Skoog (MS) taking into consideration that the species in the study belong to the same gender. The buds coming from Croton young plants producers of wine latex had the best behavior in the selected culture medium (MS + $0,01 \mathrm{mg} / \mathrm{I} A N A+0,1 \mathrm{mg} / \mathrm{I}$ of BAP and $A G 3+20 \mathrm{ml}$ of coconut water) presenting an increase
\end{abstract}


in height, number of leaves and percentage of survival in relationship to Croton producers of red and ocher latex. The plantulas of Croton producers of wine latex, previously rooted in vitro, were taken for acclimatization. Four substrates were tested, determining that the response of the plantulas changes according to the substrate composition, watering conditions (nebulization), fungus control (benlate to 0,1\%) and the application of the bioestimulant biogen 1 to 0,1\%. The chromosomal number determined in plants of the gender Croton producers of red, wine and ocher latex was of 40.

Keywords: Croton, latex, in vitro, micropropagation, seedlings, explants

\section{INTRODUCCIÓN}

El Perú es un país que tiene amplia diversidad biológica, cuya propagación de especies que se desarrollan en el bosque tiene a menudo problemas en la producción de plantones, principalmente por el bajo poder germinativo de las semillas y la mala aplicación de las técnicas de propagación por estacas e injertos. Esto tiene mayor trascendencia cuando se trata de especies que se encuentran en vías de extinción, son valiosas y están sometidas a una alta incidencia de explotación, corriéndose el riesgo de no disponer de árboles semilleros proveedores de material de propagación, como es el caso de la sangre de grado. También existen problemas relacionados con la identificación botánica: hay especímenes identificados como Croton draconoides por algunos autores y como Croton lechleri por otros. Además, la calidad del látex está relacionada con tres especies (Croton draconoides Muell. Arg., Croton lechleri Muell. Arg. y Croton palanostigma Klotzch); sin embargo, por las características del látex mismo, existen tres variedades de coloración del látex: el ocre, rojo y vino. Los estudios citogenéticos son escasos en la mayoría de especies nativas; por eso un estudio citogenético de las tres variedades de coloración de látex mencionadas es importante, pues permitirá determinar la posible relación entre las diferentes especies de Croton productores de látex e identificar el germoplasma para promover su mejoramiento hacia tipos adecuados para la producción comercial en mayor escala y con calidad seleccionada. Por otro lado, la propagación in vitro de la especie Croton es una alternativa productiva que nos permitirá una producción masiva de la misma, lo cual es una ventaja frente a los métodos tradicionales. En suma,los objetivos del presente estudio son: Determinar las diferencias en el desarrollo in vitro de yemas provenientes de plantas juveniles de
Croton productores de látex, evaluar la respuesta a la aclimatación de plántulas de Croton de mejor comportamiento in vitro y determinar el número cromosómico de individuos seleccionados del género Croton productores de látex.

\section{MÉTODO EXPERIMENTAL}

Material vegetal: El material vegetal utilizado en el presente trabajo fueron semillas de Croton productores de látex rojo y vino y plantones de Croton de látex ocre.

Medios de cultivo: Se utilizó el medio de cultivo de Murashige y Skoog (1962) con adición de diferentes concentraciones de hormonas de crecimiento (tabla 1) previa esterilización por autoclavado a 15 libras de presión por 20 minutos, a $121^{\circ} \mathrm{C}$.

Metodología para la propagación in vitro: Se trabajó con dos tipos de explantes: yemas de plántulas de Croton draconoides con las cuales se determinará el mejor medio de cultivo, y yemas de plantones de Croton productores de látex rojo, vino y ocre, las que serán introducidas en el mejor medio de cultivo por tratarse del mismo género. Las condiciones de desarrollo en cámara fue a fotoperíodo de $16 / 8$ horas (luz/oscuridad), temperatura de $25 \pm 1{ }^{\circ} \mathrm{C}$ y humedad relativa de 90 a $100 \%$.

Estandarización y optimización in vitro de yemas de plántulas de Croton:

\section{Fase de estandarización}

En esta fase se tomaron se tomaron 16 nudos de plántulas in vitro de Croton draconoides, los cuales se sembraron en los cinco medios de cultivo Murashige y Skoog indicados. Se sembró cuatro nudos por medio de cultivo, uno por tubo de ensayo. 
Tabla 1: Medios para multiplicación.

\begin{tabular}{|c|c|c|c|c|c|}
\hline \multirow[t]{2}{*}{ REACTIVOS } & \multicolumn{5}{|c|}{$\begin{array}{c}\text { MEDIOS DE } \\
\text { MULTIPLICACIÓN }\end{array}$} \\
\hline & $\mathrm{T}_{0}$ & $\mathrm{~T}_{1}$ & $\mathrm{~T}_{2}$ & $T_{3}$ & $\mathrm{~T}_{4}$ \\
\hline $\begin{array}{l}\text { Macro y micronutriente MS } \\
\text { (Murashige and Skoog) }\end{array}$ & $\mathrm{C}$ & $\mathrm{C}$ & $\mathrm{C}$ & $\mathrm{C}$ & $\mathrm{C}$ \\
\hline Glicina $(\mathrm{mg} / \mathrm{L})$ & 2,0 & 2,0 & 2,0 & 2,0 & 2,0 \\
\hline Acido nicotínico (mg/L) & 0,5 & 0,5 & 0,5 & 0,5 & 0,5 \\
\hline Piridoxina $(\mathrm{mg} / \mathrm{L})$ & 0,5 & 0,5 & 0,5 & 0,5 & 0,5 \\
\hline Tiamina $(\mathrm{mg} / \mathrm{L})$ & 0,1 & 0,1 & 0,1 & 0,1 & 0,4 \\
\hline Myo-inositol (mg/L) & 100 & 100 & 100 & 100 & 100 \\
\hline Acido fólico $(\mathrm{mg} / \mathrm{L})$ & & & & & 1,0 \\
\hline L-Arginina (mg/L) & & & & & 4,0 \\
\hline Pantotenato de Calcio (mg/L) & & & & & 2,0 \\
\hline $\begin{array}{l}\text { Ac. alfa-naftaléno acético } \\
(\text { ANA })(\mathrm{mg} / \mathrm{L})\end{array}$ & & & 0,01 & 0,01 & \\
\hline Ac. Giberélico $\left(\mathrm{AG}_{3}\right)(\mathrm{mg} / \mathrm{L})$ & & 0,1 & 0,1 & & \\
\hline 6-bencilaminopurina $(\mathrm{BAP})(\mathrm{mg} / \mathrm{L})$ & & 0,01 & 0,1 & 0,01 & \\
\hline Agua de coco $(\mathrm{ml} / \mathrm{L})$ & & 20 & 20 & 20 & 20 \\
\hline Sucrosa $(\mathrm{g} / \mathrm{L})$ & & 20 & 20 & 20 & 20 \\
\hline Phytagel $(\mathrm{g} / \mathrm{L})$ & 2,5 & 2,5 & 2,5 & 2,5 & 2,5 \\
\hline $\mathrm{pH}$ & & & $5,6-5$ & & \\
\hline
\end{tabular}

$\mathrm{C}=$ Completo

\section{Fase de optimización}

En este proceso se realizaron subcultivos de las plántulas sobrevivientes de la fase de estandarización y otras plántulas de la misma especie. Se utilizó los mismos medios de cultivo utilizados en la fase anterior; se sembró 75 nudos, 15 por tratamiento. El mejor tratamiento de esta etapa fue utilizado para la introducción de yemas provenientes de plantones de sangre de grado productores de látex color rojo, vino y ocre.

\section{Desinfección y establecimiento in vitro de yemas procedentes de plantones de Croton productores de látex rojo, vino y ocre}

Los explantes fueron sumergidos en agua con detergente por espacio de tres minutos; ya enjuagadas se los llevó a cámara de flujo para desinfectar utilizando alcohol al $70 \%$ por espacio de 20 segundos e hipoclorito de sodio al 2,75\%, entre tres a 10 minutos. Después de tres enjuagues con agua destilada se colocó los explantes en hipoclorito de $5,25 \%$, diluido al $0,5 \%$ por tres minutos.

\section{Enraizamiento de plántulas de Croton productores de látex color vino}

Para la aclimatación, se transfirieron 150 plántulas de Croton productoras de látex color vino desarrolladas in vitro, con un tamańo promedio de cuatro centímetros a un medio de enraizamiento (MS con adición de $0,01 \mathrm{mg} / \mathrm{l}$ de ANA y $0,1 \mathrm{mg} / \mathrm{l}$ de $\mathrm{AG}_{3}$ ).

\section{Aclimatación}

Se tomaron 100 plántulas in vitro de Croton productor de látex vino, con buenas raíces y brotes foliares para ser sometidas a proceso de aclimatación utilizando diferentes substratos previamente autoclavados: tierra agrícola, musgo, arena de río (1:1:1); tierra agrícola, arena de río; tierra agrícola, musgo; musgo, arena de río (1:1).

Se preaclimató, haciendo agujeros sobre las tapas de platino de los frascos conteniendo a las plántulas enraizadas, días antes de llevar al invernadero. Las raíces de las plántulas después de lavadas con agua destilada para liberar el agar, fueron cortadas dejando $3 \mathrm{~cm}$; se utilizó benlate como funguicida y biogen 1 como bioestimulante al $0,1 \%$ por 10 minutos. La aclimatación se llevó a cabo en el invernadero entre 26 a $38^{\circ} \mathrm{C}$, con una humedad relativa del 90 a $95 \%$, la que se mantuvo con el uso de nebulización cuatro veces al día para evitar la deshidratación. Se evaluó la altura de las plantas a los 15 y 30 días y el porcentaje de plántulas sobrevivientes luego del procedimiento de aclimatación.

\section{Caracterización citogenética}

Se utilizó meristemos radiculares extraídos de plantones de Croton productores de látex rojo, vino y ocre, entre las 10:00 y 11:00 a.m. Para la prefijación y fijación se utilizó ambush 25EC a $15 \mu \mathrm{l} / 100 \mathrm{ml}$. de agua destilada en diferentes tiempos (12, 24 y 48 horas) a $4{ }^{\circ} \mathrm{C}$ y para la maceración se trabajó con $\mathrm{HCl}$ $1 \mathrm{~N}$, a temperatura constante y diferentes tiempos $(12,15,18$ minutos). La tinción se realizó con aceto orceina al $2 \%$ a diferentes tiempos (20 y 24 horas) y orceína lacto-propiónica entre tres y cinco horas de coloración, ambos a temperatura ambiente.

\section{Análisis de datos}

Para el caso de cultivo in vitro, el experimento fue conducido en un diseño completamente 
al azar (DCA) con diferente número de repeticiones.

Para la evaluación del contaje cromosómico se consideró la moda, es decir el número cromosómico más frecuentemente encontrado en la observación.

\section{RESULTADOS Y DISCUSIÓN}

\section{Desarrollo in vitro de yemas juveniles de croton productores de látex}

\section{Fase I: Estandarización a partir de yemas de plántulas producidas in vitro}

El ANVA de altura, número de nudos y número de hojas de las plántulas de Croton draconoides, de datos tomados a los 30 días de iniciado el experimento, fueron no significativos; lo que quiere decir que no se pudo demostrar que los tratamientos en estudio influyan de diferente forma con respecto a los tres parámetros tomados a consideración. Con respecto a las medias de hojas y nudos, T3 es el mejor con 2,12 y 1,87 respectivamente. En cuanto a altura, la mejor media la tuvieron T3 y T1 $(1,60$ $\mathrm{cm}$ ambos) (gráfico 1). Sin embargo, con respecto a la emergencia, diferenciación y sobrevivencia, los mejores fueron T2 y T4 (100\%), seguidos de $\mathrm{T} 1$ con un $100 \%$ de emergencia y diferenciación, sobreviviendo un 75\%; T3 con un 50\% en los tres parámetros y T0 con un 75\% de emergencia, un $50 \%$ de diferenciación y un $25 \%$ de sobrevivencia (gráfico 2). Esto podría deberse al escaso número de repeticiones y a los diferentes números de repeticiones debido a la mortandad. Calzada [1] menciona que las comparaciones entre tratamientos que tienen menos repeticiones son menos precisas que entre las que tienen más repeticiones.
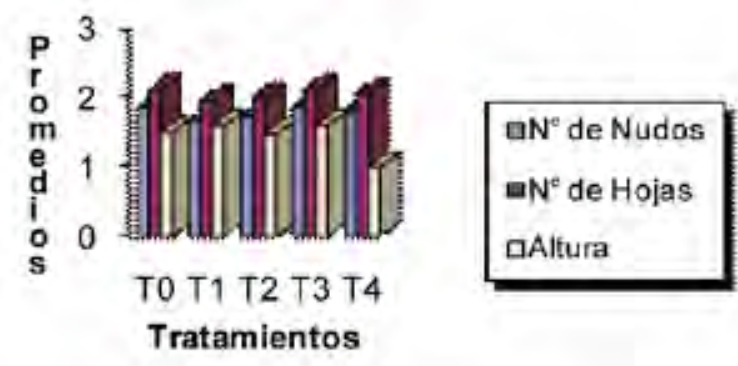

Gráfico 1: Influencia de los tratamientos sobre el número de nudos, número de hojas y altura de plántulas de Croton draconoides a 30 dias de propagación.

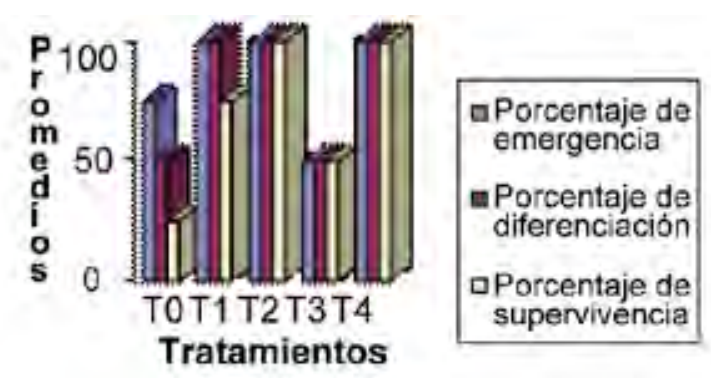

Gráfico 2: Influencia de los tratamientos sobre el porcentaje de emergencia, diferenciación y supervivencia de plántulas a partir de yemas de Croton draconoides.

\section{Fase II: Optimización a partir de yemas producidas in vitro}

De acuerdo al ANVA para número de nudos por plántula, se encontró diferencia estadística entre los tratamientos en estudio. Al comparar las medias (gráfico 3), el mayor número de nudos se obtuvo con el tratamiento T2 $(2,000)$, seguido de T4 (1,7609), T3 (1,7550), T1 (1,7390) y T0 $(1,7367)$; para número de hojas fue no significativo, lo que quiere decir que no se pudo probar que los tratamientos tuvieron influencia con respecto al número de hojas. Al comparar las medias, T2 tuvo un valor relativamente más alto $(2,3892)$, seguido de T3, T0, T1 y T4 con 2,29336, 2,2860, 2,2200 y 2,0855 , respectivamente.

Con respecto a la altura de plántula, se obtuvo una diferencia altamente significativa, lo que nos indica que los tratamientos han influido con diferente intensidad en el crecimiento de las plántulas.

De acuerdo a la prueba de Duncan al comparar las medias (gráfico 3), T2 y T4 obtuvieron los mayores promedios de altura con 2,9462 y 2,4364, respectivamente. En cuanto al porcentaje de sobrevivencia, T2 obtuvo el mayor número de sobrevivencia (86,67\%). Pierik [2] manifiesta que en el cultivo in vitro de plantas superiores, los reguladores, especialmente las auxinas $\mathrm{y}$ citoquininas, juegan un papel muy importante. Esto es corroborado por Bidwell [3], quien recomienda el uso de auxinas, citoquininas y giberelinas en forma balanceada y conjunta, pues separadamente cada una de estas hormonas causa anormalidades o retardos en el desarrollo del embrión. Asimismo, sostiene "que el balance o interacción de las hormonas, más que la suma de sus acciones individuales, es lo que da la clave del desarrollo". 
El tratamiento T2, a diferencia de los demás tratamientos, contiene ácido naftaleno acético (ANA), bencilaminopurina (BAP) y ácido giberélico (AG3), y es posiblemente la razón por la que muestra un mejor desarrollo de Croton a partir de yemas en el presente estudio.
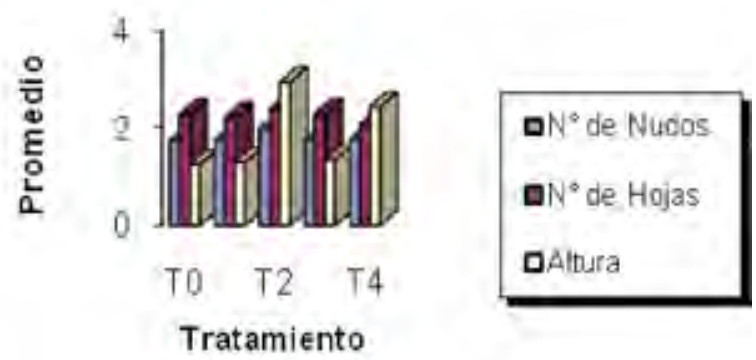

Gráfico 3: Efecto de los medios de cultivo sobre la altura, número de nudos, número de hojas de plántulas Croton draconoides.

\section{Introducción in vitro de yemas de Croton productores de látex rojo, vino y ocre}

Antes de la introducción, se desinfectó las yemas, obteniéndose un mayor porcentaje de desinfección en Croton productor de látex vino con un $96 \%$. Sin embargo, el de látex color rojo tuvo un porcentaje bastante alto que no se contaminó (90\%) (gráfico 4).

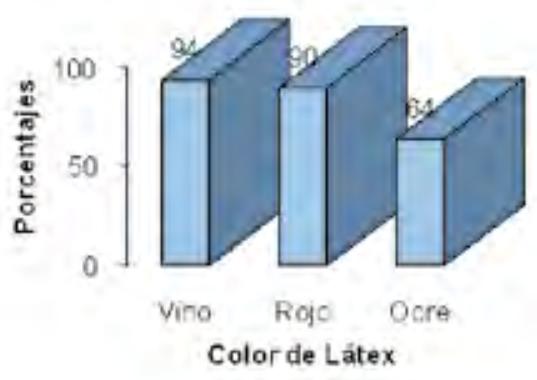

Gráfico 4: Efecto de la desinfección sobre yemas procedentes de Croton productores de látex rojo, vino y ocre.

Hartmann y Kester [4] manifiestan que para la propagación de tallos, el procedimiento de desinfección debe iniciarse sumergiendo a los explantes en alcohol (70 al 95\%) para darles una esterilización superficial preliminar. Del mismo modo, Abedini [5] indica que probó diferentes concentraciones de etanol para la desinfección de Eucaliptus viminalis Labill y que el mejor resultado obtenido fue el de la inmersión del material vegetal en etanol al $70 \%$ durante tres minutos. Para Donayre
[6], sumergir los explantes de sangre de grado en hipoclorito de sodio al $0,5 \%$ de tres a cinco minutos y luego sembrarlos es un buen complemento en el proceso de desinfección; por ello se utilizó este proceso. Las diferencias en porcentaje de desinfección posiblemente se deba a que las yemas de Croton productores de látex rojo y vino fueron obtenidas de plantones de invernadero y las yemas de Croton productores de látex ocre fueron extraídas de plantones recolectados del campo, con una edad aproximada de tres meses. Según Roca y Mroginski [7], los explantes provenientes de vegetales que crecen en invernaderos o en cuartos climatizados son relativamente más fáciles de desinfectar que los provenientes de plantas que crecen en el campo.

\section{A. Evaluación del crecimiento de plántula in vitro de Croton productor de látex}

En esta fase, el Análisis de Variancia para número de nudos y número de hojas de la plántula fue no significativo, de tal forma no se pudo demostrar diferencia estadística entre los tratamientos en estudio. Al comparar las medias (gráfico 5), el mayor número de nudos se obtuvo con el Croton productor de látex rojo (2,2756), estadísticamente al mismo nivel que el productor de látex vino $(2,2647)$ y ocre $(2,1558)$. En cuanto a hojas, el mayor número lo tuvo el Croton productor de látex vino $(2,4702)$, no muy distante del productor de látex rojo $(2,4597)$ y ocre $(2,3600)$.

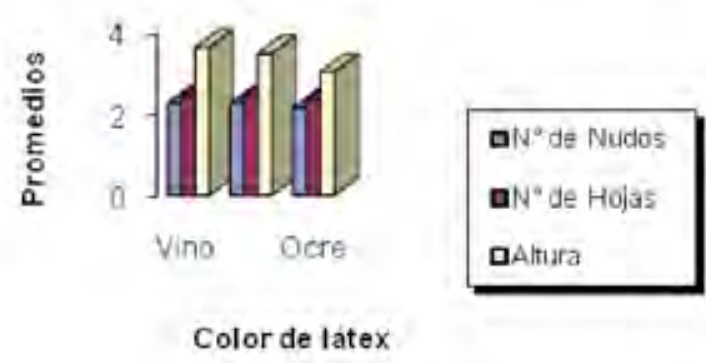

Gráfico 5: Altura, número de nudos, número de hojas de plántulas de Croton productores de látex en cultivo in vitro.

Con respecto a la altura de plántula, se obtuvo una diferencia estadística significativa; lo que nos indica que los tratamientos han influenciado indistintamente sobre la altura de las plántulas. De acuerdo a la prueba de Duncan al comparar las medias, el Croton productor de látex vino tuvo relativamente el mejor promedio de altura $(3,66)$. 
En cuanto al porcentaje de sobre vivencia, el Croton productor de látex vino tuvo mayor porcentaje $(90 \%)$ en relación a rojo $(78 \%)$ y ocre $(62 \%)$.

Estadísticamente, los Croton productores de látex rojo, vino $\mathrm{y}$ ocre tuvieron muy similar comportamiento en cultivo in vitro; sin embargo, en términos generales fue el Croton productor de látex vino el que mejor comportamiento tuvo.

Lograr el $64 \%$ de sobrevivencia como mínimo correspondiente al Croton productor de látex ocre es bastante significativo, considerando que las plantas leñosas son difíciles de manipular in vitro, y que, en general, los árboles se multiplican lentamente ya que tienen ciclos de latencia complicados [8]. Debe tenerse en cuenta que el material juvenil utilizado favorece estos resultados. Rao y Lee [9] mencionan que cuanto más joven sea el tejido de un árbol, mejor será su crecimiento al cultivarse in vitro, pues los tejidos u órganos de árboles adultos tienen un potencial morfogenético limitado. Manifiesta Suárez [10] que Morán (1981) trabajó con yemas de entrenudos en especies leñosas utilizando el medio básico de Murashige y Skoog (1962) con las variantes de sustancias de crecimiento, que son la quinetina, la bencilaminopurina y el ácido giberélico, obteniendo varias yemas a los 45 días de sembrados los explantes.

\section{B. Evaluación del enraizamiento de plántula in vitro de Croton productor de látex vino}

Se utilizó el medio determinado por Donayre [6]. Según Murashige y Skoog (1962), para mejorar el establecimiento in vivo de plantas producidas in vitro, el enraizamiento debería tener lugar en un medio pobre de sales. Se sembró 150 plántulas de las cuales enraizaron 104 (69,33\%), lo que podría considerarse un porcentaje bastante óptimo debido a que, especialmente en el caso de las plantas leñosas, la inducción de raíces es con frecuencia muy difícil, por lo que las especies leñosas son ahora enraizadas más frecuentemente in vivo que in vitro, además que así se evita mano de obra [2].

\section{Respuesta a la aclimatación de croton productor de látex color vino}

El proceso de aclimatación se realizó bajo condiciones de verano, previo enraizamiento de las plántulas en cultivo in vitro. El control de patógenos se efectuó con un benlate al $0,1 \%$ (funguicida), con inmersión de las raíces por 10 minutos previa a la siembra y el uso de biogen 1 al $0,1 \%$ como bioestimulante, lo cual fue muy importante en la sobrevivencia de las plantas. Se controló la humedad relativa (90 a 95\%) para evitar la deshidratación de las plántulas con el uso de riego por nebulización y una temperatura óptima dentro del invernadero. Se evaluó la altura de las plantas a los 15 y 30 días de la siembra y el porcentaje de plántulas sobrevivientes luego del procedimiento de aclimatación.

De acuerdo al cuadro comparativo de altura de plantas (gráfico 6), se pudo verificar que las plantas lograron mayor altura en el transcurso de los días de la aclimatación, lo que nos permite afirmar que hubo una respuesta favorable al proceso de aclimatación.

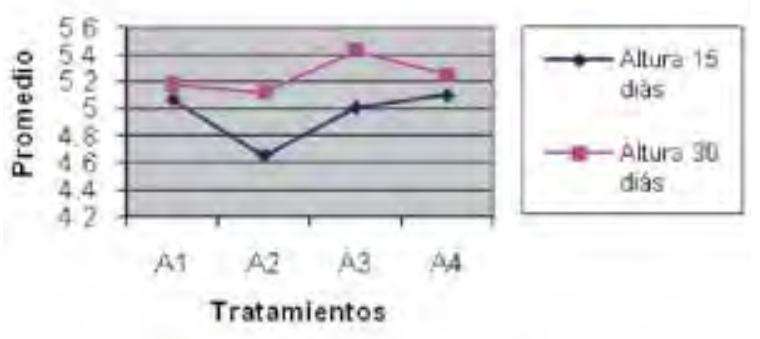

Gráfico 6: Cuadro comparativo de altura de planta a los 15 y 30 dias después del transplante.

Duque y Pierre [11] manifiestan que la aclimatación de la achira se ha logrado sumergiéndole las raíces en una solución de funguicida (Vitavax $5 \mathrm{~g} / \mathrm{l}$ ) y sembrándola en macetas pequeñas con sustrato previamente desinfectado.

Según Abedini [5], se llevaron a tierra plántulas in vitro de Eucaliptus sp. y se remetieron a condiciones de invernáculo bajo riego por niebla; en toda esta etapa las plantas fueron tratadas con pulverizaciones periódicas obteniéndose buenos resultados.

Con respecto al substrato utilizado, el tratamiento A3 (tierra-musgo) respondió con un mayor porcentaje de sobrevivencia (84\%), seguido del tratamiento A2 (arena-tierra) con un porcentaje de sobrevivencia de $76 \%$; finalmente los tratamientos A4 (arena-musgo) y A1 (tierra-musgo-arena) con 72 y $20 \%$ de sobrevivencia respectivamente (gráfico 7). Según Koevary et al. (1978), fue vital 
el uso de substrato estéril, pues al utilizar mezclas de substratos sin esterilizar es difícil obtener buenos resultados en la aclimatación de plántulas in vitro, debido a que por lo general esta práctica trae como consecuencia serios problemas de contaminación por microorganismos patógenos.

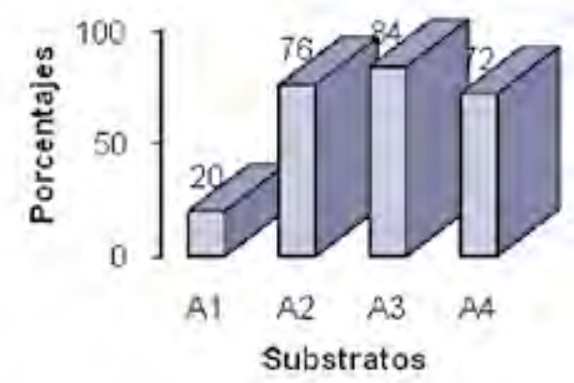

Gráfico 7: Porcentaje de sobrevivencia de acuerdo al substrato.

\section{Número cromosómico de individuos seleccionados del género Croton productores de látex}

La hora más adecuada de colección de puntas de raíz es entre las 10:00 y 11:00 a.m., pues durante esta hora ocurre una mayor frecuencia de células metafísicas [6]. El comportamiento de los cromosomas con ambush 25 ECa una concentración de $15 \mu \mathrm{l} / 100 \mathrm{ml}$ por 24 horas fue la más adecuada. Se logró una buena prefijación y fijación a la vez, pues se obtuvo alta frecuencia de metafase y buena dispersión de los cromosomas. Watanabe y Orillo [13] obtuvieron buenos resultados con ambush 25 EC como prefijador en papa, imitando a Klein [14], quien lo utilizó en Allium cepa L. Ambos autores obtuvieron igualmente buena cantidad de metafase. Mientras que para el caso de Physalis peruviana, el uso de 8-hidroxiquinoleina a una concentración de $0.002 \mathrm{M}$ y $0.003 \mathrm{M}$ por $4: 00$ a $6: 00$ horas $\mathrm{y}$ ambush a una concentración de $15 \mu \mathrm{l} / 100 \mathrm{ml}$ fue óptimo como prefijador (Alarcón, 2002). Se confirma el uso estándar de $\mathrm{HCl} 1 \mathrm{~N}$ como agente hidrolizante durante 18 minutos a $60^{\circ} \mathrm{C}$. Se pudo observar que a menos tiempo de exposición, no hay suficiente hidrólisis del tejido meristemático, el cual permanece aún duro y las células no se dispersan luego del aplastado; a mayores tiempos de exposición, se manifiesta una sobrehidrólisis dando como resultado una excesiva disgregación celular luego del aplastado. Los resultados nos muestran que para el contaje de cromosomas resulta mejor colorear las puntas de las raíces con orceína lactopropiónica por espacio de cuatro horas. En base a la observación y análisis de 20 células metafásicas para cada individuo en estudio, se determinó que el número de cromosomas de Croton productores de látex vino, rojo y ocre es $2 \mathrm{n}=40$. Se eligieron en el campo del microscopio las células con cromosomas bien distribuidos y definidos, asegurando así que se estudiaran células enteras, como recomiendan Savidan y Pernés [15].

Darlington [17] reporta que el género Croton tiene un número básico de $\mathrm{x}=8$, y que Croton glandulosus, Croton monanthogynus y Croton palmeri tienen un número de cromosomas $\mathrm{x}=8$ y $2 \mathrm{n}=2 \mathrm{x}=16$. $\mathrm{El}$ número cromosómico de Croton lecleiri MuellArg es de 32 y postula que sería tetraploide [6]. De acuerdo con el análisis molecular realizado por Domínguez [18] con el ensayo RAPD ${ }_{s}$, AFLPs, para el conjunto de ambos marcadores, no se encuentra ningún indicio que permita afirmar que exista algún tipo de diferencia en los marcadores encontrados entre plantas de sangre de grado productoras de látex rojo y vino, de tal manera que las diferencias morfológicas y de color de látex existente se deben a factores ambientales.

Figura 1: Células en estado metafásico de Croton productor de látex.

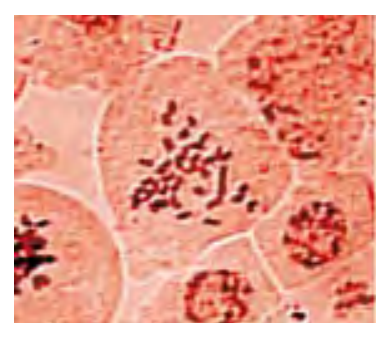

ROJO

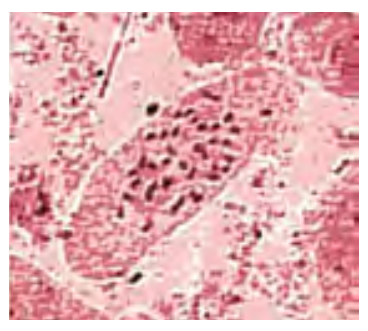

VINO

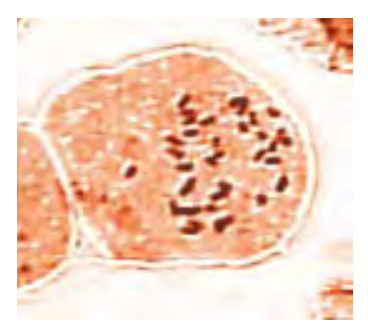

OCRE 


\section{CONCLUSIONES}

Las plántulas de Croton productores de látex color vino fueron las que mejor respondieron al cultivo in vitro, lo que se manifiesta en el mayor número de hojas, altura y mayor porcentaje de sobrevivencia en relación al Croton productores de látex color rojo y ocre.

En la aclimatación de plantas de Croton productores de látex color vino se observó que el porcentaje de sobrevivencia estuvo influenciado por el tipo de substrato.

El número cromosómico determinado fue de 40 en Croton sp productores de látex rojo, vino y ocre.

\section{AGRADECIMIENTOS}

Nuestro sincero agradecimiento a la Universidad Nacional de San Martín, Tarapoto, y a la Universidad Nacional Agraria, La Molina, por las facilidades brindadas para la ejecución del presente trabajo de investigación.

\section{REFERENCIAS}

[1] B. Calzada, Métodos Estadísticos. Universidad Nacional Agraria-La Molina, Lima, Perú, 1970.

[2] R.L.M. Pierik, Cultivo in vitro de las Plantas Superiores, Ediciones Mundi-Prensa, Madrid, España, 1990.

[3] S. Bidwell,Fisiología Vegetal, 1ra. Ed., AGT Editor S.A., 1985, 622-625.

[4] T. Hartmann y D. Kester, Propagación de Plantas. Principios y Prácticas, México, 1995, 42-45.

[5] W. Abedini, Micropropagación in vitro de Eucaliptus viminalis Labill. Experiencias Forestales. Bosques y Desarrollo. Legislación Forestal: Por Reglas claras de juego, Argentina, s/f, 48-49.

[6] M. L. Donayre, Avances en la Caracterización Citogenética y Respuestas al Cultivo in vitro en dos especies del Género Croton (Sangre de Grado),Tesis para optar el grado de Magister Scientiae,
Universidad Nacional Agraria-La Molina, Lima, Perú, 2002.

[7] W. Roca y L. Mroginski, Cultivo de Tejidos en la Agricultura, CIAT, 1991, 20-35.

[8] R. H. Zimmerman, "Application of tissue culture propagation to woody plant", in: Tissue culture in forestry and agriculture, Ed. by R. R. Henke, K. W. Hughes, M. J. Constanti: A. Hollaender, New York, Plenum Press, 1985, 165-177.

[9] Rao y Lee (1982), Importance of tissue culture in tree propagation, in International Congress of plant, Tissue and Cell culture, Tokio,Japan, Ed. By A. Fugiwara, Japanese Association for Plant tissue Culture, 1982, 715-718.

[10] E. O. Suárez, Cultivo in vitro de segmentos de chirimoya (Annona cherimola Mill), Tesis para optar el grado de Agrónomo, UNALM, Lima, Perú, 1990, 13-15.

[11] L. Duque y L. Pierre, Introducción, micropropagación, conservación in vitro y aclimatación a invernadero de Canna edulis. Raíces y tubérculo Andinos. Avances de investigación I, Centro Internacional de la Papa, Lima, Perú, 1999.

[12] K. Koevary, L. Pappaport y L. Morris, Tissue Culture propagation of head lettuce. Hort. Science 13 (1978):39-41.

[13] K. N. Watanabe y M. Orrillo, An alternative pretreatment meted for mitotic chromosome observation in potatos, American Potato Journal, 1993, 70(7):543-548.

[14] M. Klein, C-mitotic action of the insecticide Ambush 25 EC in Allium cepa L. Genética Polonica 1990, 3(2):107-113.

[15] Y. H. Savidan y J. Pernés, Diploid-Tetraploiddihaploid cycles and the evolution of Panicum maximum Jacq. Evolution (1982) 36 (3):596-605.

[17] C. D. Darlington y A. P. Wylie, Chromosome Atlas of flowering plants, 1955.

[18] A. Domínguez, Caracterización molecular de Croton sp "Sangre de grado" de uso medicinal mediante marcadores $\mathrm{RAPD}_{S}$ y $\mathrm{AFLP}_{\mathrm{S}}$, Tesis para optar el Título de Biólogo, Universidad Nacional Agraria- La Molina, Lima, Perú, 2002.

E-mail: thirtsa_@hotmail.com 